\title{
Clambunk skidder: avaliação econômica no arraste de madeira ${ }^{1}$
}

\section{Clambunk skidder: economical evaluation in drags of wood}

\author{
Robson José de Oliveira ${ }^{2 *}$; Carlos Cardoso Machado ${ }^{3}$; \\ Haroldo Carlos Fernandes ${ }^{4}$; Juliana Lorensi do Canto ${ }^{5}$
}

\section{Resumo}

O presente estudo teve como objetivo avaliar economicamente a atividade de arraste em áreas montanhosas, utilizando-se um trator florestal arrastador com esteiras (Clambunk skidder). O estudo foi conduzido em povoamentos de eucalipto de uma empresa florestal do Estado de Minas Gerais, no sistema de colheita de árvores inteiras. A avaliação econômica consistiu na determinação dos custos operacionais e da distribuição destes custos. A produtividade do Clambunk skidder variou de 18,34 a $72,08 \mathrm{~m}^{3} \cdot \mathrm{h}^{-1}$, com custo operacional de $\mathrm{R} \$ 268,61$ por hora efetiva.

Palavras-chave: Colheita, produtividade, custos

\begin{abstract}
The present study had the objective of evaluating economical performance of Clambunk skidder in $\log$ drags activities. The study was developed in an eucalyptus crop property of a Minas Gerais State company that uses a mechanized full-tree system of harvest. The economical evaluation was made with the operational costs determination. The productivity varied from 18.34 to $72.08 \mathrm{~m}^{3} \cdot \mathrm{h}^{-1}$ and the effective operational cost was of R $\$ 268.61$ / hour.
\end{abstract}

Key words: Harvesting, productivity, costs

\section{Introdução}

A colheita e o transporte florestal, por serem responsáveis por mais de $50 \%$ do custo final da madeira posta na indústria, têm exigido pesquisas visando busca de melhorias para otimizar a colheita florestal e redução de todo o processo florestal. Atualmente, a mecanização das atividades de colheita florestal vem se tornando cada vez mais constantes pelas maiorias das empresas florestais, que buscam a cada dia novas tecnologias para aumentar a produtividade e reduzir custo. Com a evolução natural dos sistemas mecanizados de colheita florestal no Brasil, onde diversos equipamentos são importados, e muitas vezes adaptados, não se consegue atingir o mesmo desempenho operacional que em seus países de origem, devido às diferenças edafoclimáticas e, a escassez de pesquisas operacionais antes da introdução de um determinado equipamento (MACHADO, 1989).

Áreas acidentadas, condições topográficas desfavoráveis, exigem um nível de planejamento mais apurado, bem como o desenvolvimento de

1 Pesquisa Financiada pela Capes.

2 Doutorando em Ciência Florestal no Departamento de Engenharia Florestal da Universidade Federal de Viçosa - UFV, ViçosaMG. E-mail: robinhojo@yahoo.com.br

3 Professor do Departamento de Engenharia Florestal da Universidade Federal de Viçosa - UFV, Viçosa-MG.

4 Professor do Departamento de Engenharia Agrícola da Universidade Federal de Viçosa - UFV, Viçosa-MG.

5 Doutoranda em Ciência Florestal no Departamento de Engenharia Florestal da Universidade Federal de Viçosa - UFV, ViçosaMG. E-mail: jlcanto@terra.com.br

* Autor para correspondência 
equipamentos específicos para a colheita de suas florestas na tentativa de redução de custos para que haja um crescimento na produtividade para assegurar o abastecimento da indústria (LEITE, 1992).

A movimentação das madeiras por meio de arraste, suspensa por teleféricos ou em tratores autocarregáveis logo após o corte até a margem das estradas recebe o nome de extração ou arraste que é uma operação que exige um planejamento detalhado desde a escolha das máquinas próprias dentro do sistema mais indicado de trabalho. Atualmente, no Brasil, a extração mecanizada é realizada por meio de "skidders" e "forwarders". O skidder apareceu na década de 60 , sendo um trator potente, fácil de operar e econômico. É uma máquina que pode trabalhar com diferentes tamanhos de árvores. Tratase de um trator florestal arrastador, desenvolvido exclusivamente para o arraste de madeira. Possui uma cabine com grande mobilidade dentro da área de corte, tem o chassi articulado, tração $4 \times 4$, rodados de pneus e/ou esteiras. Alguns modelos são dotados de uma garra traseira telescópica que é acionada pelo sistema hidráulico ou sistema de cabos de aço para que seja realizado o arraste de feixes de toras sendo assim chamados de clambunk skidder. (MACHADO, 2002). As principais vantagens do "clambunk skidder" segundo Oliveira (2003), são: a máquina base pode voltar a operar como "forwarder"; o volume da madeira extraída por ciclo permite operar em distâncias maiores das que as convencionais; contribui para a redução da densidade de estradas florestais; pode operar inserido em vários sistemas tais como em conjunto com harvester, feller, derrubada manual, escavadeira com cabeçote, garra traçadora, slasher, mini-slasher, traçamento na estrada, e outros; excelente do ponto de vista ergonômico; possui pneus largos com maior área de contato com o solo resultando em tração eficiente e melhor estabilidade em terrenos acidentados ou com baixa sustentação; promove baixa compactação no solo, o que acarreta em menos danos à regeneração natural no caso de florestas nativas (OLIVEIRA, 2003).
Existem inúmeros fatores que afetam a colheita florestal, os quais podem ser classificados em: biológicos, ambientais, técnicos, humanos e econômicos. Dentre os fatores econômicos que podem afetar a colheita florestal podemos destacar entre outros os seguintes: Volume de recursos, que refere-se à disponibilidade, crédito, prazos de pagamento, fluxo de caixa, endividamento a curto e longo prazos e geração líquida de caixa; Custos financeiros, que se refere aos custos de oportunidade, custos operacionais, ponto ótimo de reposição, custos de manutenção e custo unitário de produção. (SANTOS, 2000).

Os aspectos técnicos, econômicos, ambientais, biológicos e humanos devem ser considerados no planejamento da colheita florestal, pois são fatores que influenciam na produtividade e no custo, além da satisfação dos operadores (SANT'ANNA et al., 2000).

Sendo assim, entre os objetivos deste trabalho procurou-se avaliar economicamente a atividade de arraste de madeira de eucalipto em região acidentada com uso do "Clambunk skidder", determinando os custos operacionais e o custo de produção em diferentes condições operacionais;

\section{Material e Métodos}

Área de estudo

O experimento foi conduzido em florestas comerciais de Eucalipto, da empresa CENIBRA localizada na região do Vale do Rio Doce, nos municípios de Peçanha e Divinolândia de Minas, em MG, em um local com latitude de Guanhães em áreas da CENIBRA - Celulose Nipo-Brasileira S. A. Essa regional tem uma Latitude de $18^{\circ} 46^{\prime} 48^{\prime \prime}(\mathrm{S})$ e Longitude de $42^{\circ} 56^{\prime} 38^{\prime \prime}$ (W). O relevo varia de suave ondulado a forte ondulado, apresentando solos profundos, argilosos e férteis, e uma precipitação anual em torno de $1184(\mathrm{~mm})$, umidade relativa de $62 \%$ e uma temperatura em média de $27^{\circ} \mathrm{C}$. Os talhões avaliados e suas respectivas características com dados de inventário estão apresentadas no Tabela 1. 
Tabela 1. Características das áreas de coleta de dados.

\begin{tabular}{ccccccc}
\hline Talhão & Projeto & Altitude $(\mathrm{m})$ & Cidade & Área $(\mathrm{ha})$ & Produtividade $\left(\mathrm{m}^{3} / \mathrm{ha}\right)$ & $\mathrm{N}^{\mathrm{o}}$ arv $/ \mathrm{m}^{3}$ \\
\hline 2 & Caraúna & $735-919$ & Peçanha & 21,80 & 331,47 & 3,6 \\
2 & Pantanal & $770-950$ & Peçanha & 16,50 & 433,27 & 3,6 \\
108 & Sapucaia & $840-982$ & Peçanha & 31,10 & 499,39 & 2,5 \\
109 & Sapucaia & $840-982$ & Peçanha & 50,60 & 452,25 & 3,1 \\
112 & Sapucaia & $840-982$ & Peçanha & 28,60 & 464,65 & 2,9 \\
29 & Córr. das Pedras & $764-941$ & Divinolândia de Minas & 25,60 & 280,94 & 4,5 \\
31 & Córr. das Pedras & $764-941$ & Divinolândia de Minas & 40,20 & 284,35 & 4,1 \\
\hline
\end{tabular}

$\mathrm{Na}$ determinação do custo operacional considerou-se apenas o tempo total de trabalho, ou seja, não analisando as etapas do ciclo operacional da máquina. Foram feitos cálculos de custos fixos (CF) e variáveis $(\mathrm{CV})$ para determinar o custo operacional da máquina. Foi utilizado o método contábil, com valores estimados e reais, conforme metodologia proposta pela FOOD AND AGRICULTURAL ORGANIZATION - FAO (1974), e citada por Machado e Malinovski (1988).

\section{Custos Operacionais}

Os custos operacionais se dividem em custos fixos e variáveis.

Os custos fixos são aqueles que não variam com as horas de operação, não sendo afetados pela intensidade de utilização da máquina. Os custos fixos são compostos de custo de depreciação e juros.

a) Depreciação (Dp): Está associado com o desgaste natural através do tempo de uso da máquina, sendo assim um modo de se recuperar o investimento original de uma máquina. A inclusão do seu valor no custo operacional representa a constituição de um capital de reserva para aquisição de uma nova máquina. Para cálculo da depreciação foi utilizado o método da depreciação linear:

$$
D p: \frac{V a-V r}{N^{*} h e}
$$

em que: $D p=$ depreciação linear da máquina (US\$. $\left.\mathrm{he}^{-1}\right) ; V a=$ valor de aquisição da máquina (US\$);
$V r=$ valor residual da máquina $\left(\mathrm{US} \$ . \mathrm{he}^{-1}\right) ; N=$ vida útil estimada (anos); e he = horas efetivas de uso anual.

b) Juros: Foram calculados pela aplicação de uma taxa de juros ao investimento, correspondente ao capital emprestado de agência financeira:

$$
J=\frac{(C a \times i)}{V u}
$$

em que: $\mathrm{J}=$ juros sobre o capital empregado (US\$. he $\left.{ }^{-1}\right) ; C a=$ custo de aquisição da máquina (US\$); $i=$ taxa anual de juros (\%); e $V u=$ vida útil da máquina (horas).

Os custos variáveis são os custos que variam, proporcionalmente, com a quantidade produzida ou com o uso da máquina. Fazem parte deles os custos de combustíveis, lubrificantes, pneus/esteira, remuneração de pessoal e manutenção/reparos ou peças.

a) Custo de combustível (CC): é o custo referente ao consumo de óleo diesel sendo calculado pela equação:

$$
C C=P u x C
$$

em que: $C C=$ custo de combustível (óleo diesel) $\left(\mathrm{US} \$ . h \mathrm{e}^{-1}\right) ; P u=$ preço de um litro de óleo diesel (US\$.L $\mathrm{L}^{-1}$ ); e $c=$ consumo de óleo diesel por hora efetiva $\left(1 . h \mathrm{e}^{-1}\right)$.

b) Custo de lubrificantes (óleos e graxas) (CLG): é o custo referente ao consumo de óleos lubrificantes e graxas. Considerou-se que esses custos equivale a um índice fornecido pela empresa de $54 \%$ do 
custo gasto com combustível, mas esse índice pode ser calculado pela seguinte fórmula:

$$
C L G=I L G \times C
$$

em que: $C L G=$ custo com lubrificantes (US\$.he ${ }^{-1}$ ); $I L G=$ índice de custos com lubrificantes; e $C=$ custos com combustíveis (US\$.he $\mathrm{e}^{-1}$ ).

c) Custo de pneus/esteiras (CPE): é o custo referente aos pneus ou esteiras. Este custo pode ser afetado pelas condições do terreno, ambiente, manutenção dos pneus e habilidade do operador, sendo calculado pela fórmula:

$$
C P E=\frac{N p e \times V p e}{H}
$$

em que: $C P E=$ custo de pneus/esteiras (US\$.he $\mathrm{e}^{-1}$ ); $V p e=$ valor de um pneu/esteira da máquina (US\$ a unidade); $N p e=$ número de pneus/esteiras por máquina; e $H=$ vida útil do pneu/esteira, em horas efetivas.

d) Custo de pessoal operacional (COM): refere-se aos custos com salários diretos mais os custos de benefícios e encargos sociais, como $13^{\circ}$ salário, férias, seguros, cuidados médicos, alimentação, vestuário, etc., os quais foram obtidos na empresa onde se realizou o trabalho, em valores mensais e divididos pela quantidade de horas trabalhadas por mês $(\$ / h)$.

e) Custo com manutenção e reparos (CMR): é o custo relacionado com a manutenção, peças, que as máquinas estão sujeitas durante a sua vida útil. Envolve os custos com serviços de terceiros, comboio de lubrificação e caminhão de peças e oficina que foram fornecidos pela empresa.

Os custos de administração são os custos relacionados com os trabalhos de escritório e supervisão das atividades de campo, os quais também foram obtidos na empresa onde se realizou o trabalho, neste caso considerando como $10 \%$ dos custos totais em valores mensais e divididos pela quantidade de horas trabalhadas por mês $(\$ / h)$.
O custo operacional total foi obtido pela soma dos custos fixos, variáveis e os custos de administração, ou seja:

$$
C T=C F+C V+C A
$$

em que: $\mathrm{CT}=$ custo operacional total (US\$.he-1); $\mathrm{CF}=$ custos fixos (US\$.he-1); CV = custos variáveis (US\$.he-1); e CA = custo de administração (US\$. he-1).

Considerando um histórico de dados que foi levantado em metros cúbicos de madeira amostrada por hora, a produtividade do clambunk skidder foi estimada segundo as variáveis da matriz de amostragem (que englobava cinco distâncias de arraste variando até $250 \mathrm{~m}$, três declividades variando de $0^{\circ}$ a $27^{\circ}$, com dois tipos de produtividades da floresta) e considerando o volume médio do feixe de $4,92 \mathrm{~m}^{3}$.

Custo de produção:

O custo de produção no arrste foi obtido pela equação abaixo:

$$
C E=\frac{C T}{\operatorname{Pr} o d}
$$

em que $C E=$ custo de arraste do clambunk skidder (US\$.m-3 ); $C T=$ custo operacional total do clambunk skidder (US\$.h-1); e Pr od = capacidade operacional do clambunk skidder (m3.h-1).

Disponibilidade mecânica:

A disponibilidade mecânica foi definida como sendo a porcentagem do tempo de serviço programado em que a máquina está mecanicamente apta a realizar trabalho produtivo, desconsiderando-se, portanto, o tempo em que a máquina está em conserto ou em manutenção. A empresa realiza a manutenção preventiva nos equipamentos para garantir a disponibilidade mecânica previamente estabelecida. Pode ser expressa pela seguinte expressão: 


$$
D M=\frac{H E}{(H E+T P M)} \times 100
$$

em que $D M=$ grau de disponibilidade mecânica (\%); HE = tempo de trabalho efetivo (horas); TPM = tempo de permanência em manutenção (horas).

Eficiência operacional:

A eficiência operacional é a percentagem do tempo efetivamente trabalhado, em relação ao tempo total programado para o trabalho e pode ser calculada pela fórmula abaixo:

$$
E O=\frac{H E}{(H E+H P)} \times 100
$$

em que $E O=$ eficiência operacional $(\%) ; H E=$ tempo de trabalho efetivo (horas); e $H P=$ horas paradas (horas).

\section{Equipamento analisado}

O módulo mecanizado estudado era constituído por um feller-buncher (que é um trator de esteiras com um cabeçote frontal realiza o corte acumulando várias árvores, e as depositando em um local dentro da área á $45^{\circ}$ de inclinação, formando feixes de árvores inteiras), um clambunk skidder e uma garra traçadora (máquina utilizada para pegar os feixes de toras próximos das margens da estrada, realizar o traçamento e formar pilhas de toras com 2,70m de comprimento para posterior carregamento).

O Clambunk skidder estudado era da marca Valmet, modelo 890.1, tração 8X8, de pneus com rodados revestidos de esteiras, com uma capacidade de carga de 18 toneladas. Este equipamento possuía uma garra da marca Cranab G36, com uma área em torno de $2,30 \mathrm{~m}^{2}$,
O motor é Valmet 634 DWBIE, 6 cilindros turbo $210 \mathrm{hp}(154 \mathrm{~kW})$, torque de $885 \mathrm{mN}$ a $1200 \mathrm{rpm}$, e um consumo de combustível de 16,5 L/h.

O clambunk skidder realiza o ciclo operacional da seguinte forma:

Viagem vazio: Começa quando o clambunk skidder sai da margem da estrada vazio, iniciando a etapa da viagem sem carga em direção aos feixes de árvores no interior do talhão.

Carregamento: Inicia-se com a abertura da grua carregando as árvores e as depositando dentro da garra terminando quando a garra está carregada.

Arraste: É quando a máquina começa a se deslocar com parte da carga suspensa em direção à margem da estrada.

Descarregamento: Ao se aproximar da margem da estrada o operador com a grua descarrega os feixes, depositando-os de forma que não comprometa a etapa posterior da colheita florestal.

A Figura 1 ilustra o momento em que o clambunk skidder vai iniciar um ciclo operacional.

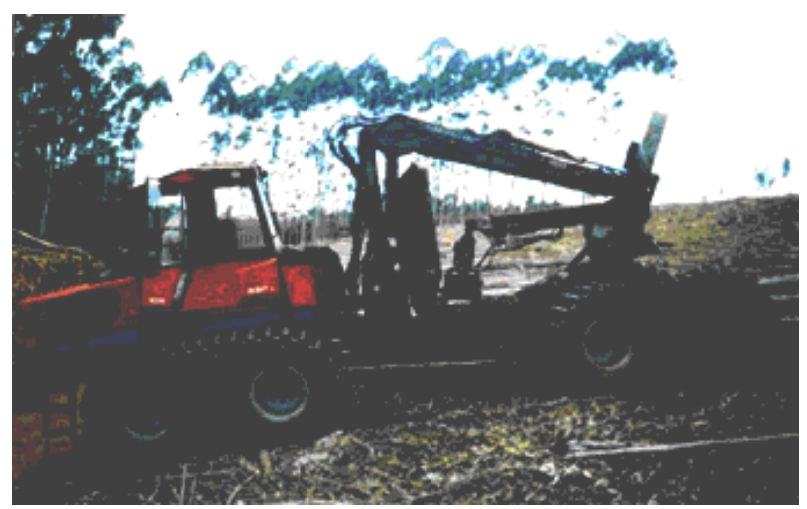

Figura 1. Clambunk skidder parado na margem do talhão. Fonte: Oliveira, 2003.

A Figura 2 ilustra o clambunk skidder realizando o arraste até a margem da estrada, com a garra cheia com os feixes de árvores para fazer o descarregamento. 


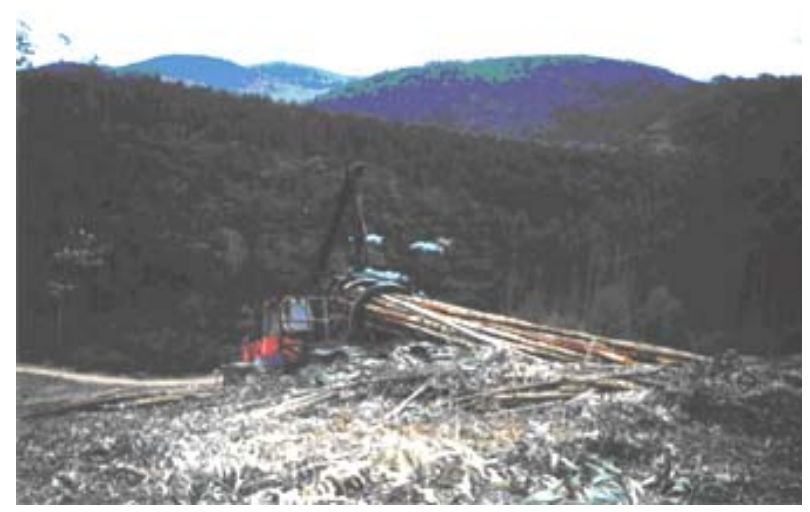

Figura 2. Clambunk skidder ealizando arraste. Fonte: Oliveira, 2003.

A Figura 3 ilustra o clambunk skidder parado realizando o descarregamento dos feixes perto da margem da estrada.

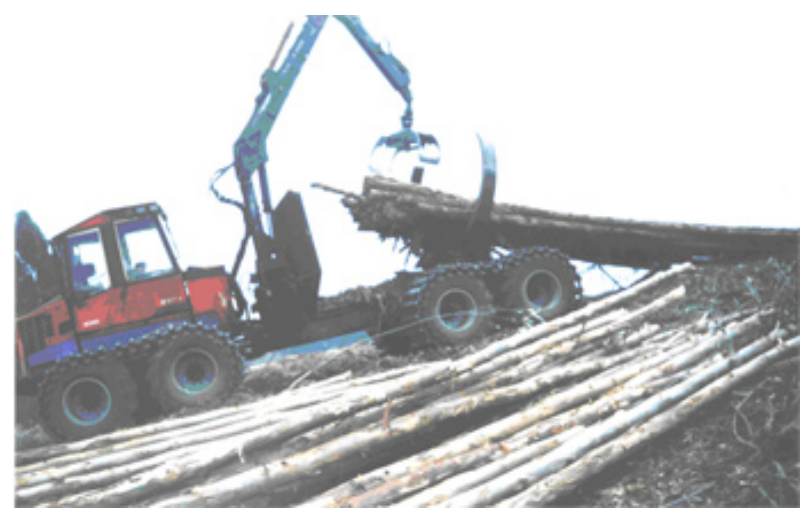

Figura 3. Clambunk skidder descarregando. Fonte: Oliveira, 2003.

\section{Coleta de dados}

Partindo de dados de inventário de alguns talhões de floresta da empresa, foi realizado um experimento usando :

Duas classes de produtividade da floresta, mas no momento da colheita dividindo as florestas em menores e maiores que $350 \mathrm{~m}^{3} / \mathrm{ha}$;

Cinco distâncias de arraste (0-50;50-100;100150;150-200;200-250 m;);

Três tipos de declividade $\left(0^{\circ}-9^{\circ} ; 9^{\circ}-18^{\circ} ; 18^{\circ}\right.$ $27^{\circ}$; sendo classificadas como suave, ondulada e acidentada respectivamente);

Com auxilio de um programa estatístico de nome Curve XP foram ajustados modelos de regressão para avaliar o efeito da distância de arraste, do declive e da produtividade da floresta sobre a produtividade da máquina obtendo várias equações, sendo escolhidas as com maior coeficiente de determinação e melhor distribuição dos resíduos.

\section{Resultados e Discussão}

\section{Estimativa da produtividade}

Na Tabela 2, abaixo estão apresentados os dados referentes aos valores em reais obtidos dos custos operacionais englobando a menor e a maior produtividade encontrada.

Tabela 2. Valores médios dos custos operacionais em reais $(\mathrm{R} \$)$

\begin{tabular}{lcccc}
\hline \multicolumn{1}{c}{ Custos operacionais } & Reais (R\$) & $\begin{array}{c}\text { Custo unitário } \\
\text { em reais (R\$) }\end{array}$ & Prod. $\left(18,34 \mathrm{~m}^{3} / \mathrm{h}\right)$ & $\begin{array}{c}\text { Prod } \\
\left(72,08 \mathrm{~m}^{3} / \mathrm{h}\right)\end{array}$ \\
\hline Depreciação & $209.504,70$ & 52,05 & 2,84 & 0,72 \\
Juros & $156.182,20$ & 38,82 & 2,12 & 0,54 \\
Custos Fixos & $365.686,90$ & 90,87 & 4,95 & 1,26 \\
Salário & $88.545,32$ & 22,01 & 1,20 & 0,31 \\
Combustível & $112.678,70$ & 28 & 1,53 & 0,39 \\
Lubrificante & $60.846,49$ & 15,12 & 0,82 & 0,21 \\
Comboio & $8.676,25$ & 2,16 & 0,12 & 0,03 \\
Peças & $246.588,80$ & 61,27 & 3,34 & 0,85 \\
Terceiros & $61.647,20$ & 15,33 & 0,84 & 0,21 \\
Pneu/esteira & $37.999,99$ & 9,42 & 0,51 & 0,13 \\
Custos Variáveis & $616.982,80$ & 153,31 & 8,36 & 2,13 \\
Custos Fixos + Custos Variáveis & $982.669,70$ & 244,18 & 13,31 & 3,39 \\
Taxa de Administração & $98.266,97$ & 24,43 & 1,33 & 0,34 \\
\hline Custo Total & $108.809,37$ & 268,61 & 14,65 & 3,73 \\
\hline
\end{tabular}


Utilizando-se uma taxa anual de juros de $12 \%$, um valor residual da máquina de $20 \%$, com o número de horas efetivas ano de 4024,24 horas, disponibilidade mecânica de 74\%, eficiência operacional de $83 \%$ e uma taxa de administração de $10 \%$ dos custos totais, calculou-se o custo por hora efetiva de trabalho sendo igual a $\mathrm{R} \$ 268,61 \cdot \mathrm{he}^{-1}$.

Considerando a variação da produtividade da máquina entre 18,34 á $72,08 \mathrm{~m}^{3} / \mathrm{h}$, obteve-se o custo por metro cúbico entre $3,72 \mathrm{R} \$ / \mathrm{m}^{3}$ e $14,64 \mathrm{R} \$ / \mathrm{m}^{3}$

Com base em dados reais contábeis e utilização das fórmulas citadas obtém-se o valor de $74 \%$ para disponibilidade mecânica e $83 \%$ para eficiência operacional.

Adistribuição dos elementos do custo operacional é ilustrada na Figura 4. Nota-se que os custos variáveis diretos (combustível, lubrificantes, peças e pneus/esteira) totalizaram $47 \%$, ou seja, quase a metade dos custos operacionais, seguidos dos custos fixos (Depreciação e Juros) que corresponderam a $37 \%$ dos custos operacionais e por último os custos variáveis indiretos (comboio, salários e terceiros) com $16 \%$.

Lopes (2007), utilizando a mesma metodologia de estudo de tempos e movimentos para máquinas florestais de arraste, encontrou para o skidder um custo por hora efetiva de trabalho de operacional de $\mathrm{R} \$ 136,33 . \mathrm{he}^{-1}$, e nesse trabalho foi encontrado que essa máquina custa quase o dobro por hora efetiva de trabalho, mas deve-se atentar para o fato de que geralmente máquinas como estas dessa pesquisa trabalha em condições topográficas mais desfavoráveis, portanto terão um custo mais elevado.

Os custos variáveis ficaram em torno de 73,32\% dos custos operacionais seguidos de $22,04 \%$ de custos fixos com 4,62\% de custos de administração.

Estimativa de tempos consumidos com as equações para o araste

Com o auxílio de uma ferramenta estatística denominada de curve expert foram geradas as eqiações de tempo abaixo representadas na Tabela 3.

Pelas equações da Tabela 3, para cada classe de floresta e declividades obtêm-se os dados de tempo que são transformados de segundo para hora, dividindo por 3600 para calcular a produtividade e pegando o volume máximo do feixe de $4,91 \mathrm{~m}^{3}$, dividindo pelo resultado citado anteriormente e chegando à produtividade, como ilustrado na Figura 5.

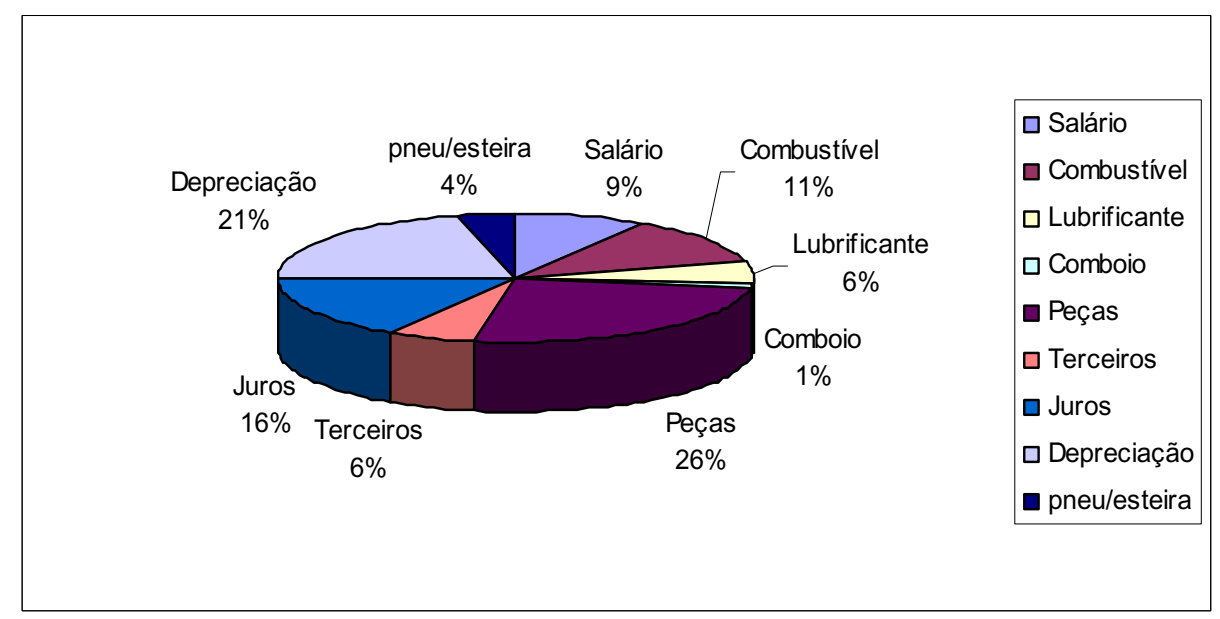

Figura 4. Porcentagem de participação dos elementos do custo operacional 
Tabela 3. Equações de tempos operacionais consumidos em função de diferentes distâncias de arraste.

\begin{tabular}{cccc}
\hline F/D* & Classe de floresta & Classe de declividade & Equação \\
\hline F1/D1 & $\left(<350 \mathrm{~m}^{3} / \mathrm{ha}\right)$ & $\left(<9^{\circ}\right)$ & $\mathrm{Y}=452,16662^{*}(1-\exp (-0,020515332 * \mathrm{DE}))$ \\
F1/D2 & $\left(<350 \mathrm{~m}^{3} / \mathrm{ha}\right)$ & $\left(10^{\circ}\right.$ a $\left.18^{\circ}\right)$ & $\mathrm{Y}=-7,05143^{*}\left(-43,829777-\exp \left(-0,016629852^{*} \mathrm{DE}\right)\right)$ \\
F1/D3 & $\left(<350 \mathrm{~m}^{3} / \mathrm{ha}\right)$ & $\left(19^{\circ}\right.$ a $\left.27^{\circ}\right)$ & $\mathrm{Y}=218,2631^{*} \exp (0,0047558563 * \mathrm{DE})$ \\
F2/D1 & $\left(>350 \mathrm{~m}^{3} / \mathrm{ha}\right)$ & $\left(<9^{\circ}\right)$ & $\mathrm{Y}=1245,963 *(1-\exp (-0,0043836854 * \mathrm{DE}))$ \\
F2/D2 & $\left(>350 \mathrm{~m}^{3} / \mathrm{ha}\right)$ & $\left(10^{\circ}\right.$ a $\left.18^{\circ}\right)$ & $\mathrm{Y}=465,8+(0,33542857 * \mathrm{DE})+0,00662857^{*}(\mathrm{DE})^{2}$ \\
F2/D3 & $\left(>350 \mathrm{~m}^{3} / \mathrm{ha}\right)$ & $\left(19^{\circ}\right.$ a $\left.27^{\circ}\right)$ & $\mathrm{Y}=1158,1816^{*} \operatorname{EXP}(-57,902117 / \mathrm{DE})$ \\
\hline
\end{tabular}

*F/D =Classe de Produtividade da Floresta / Classe de Declividade; F1D1 = Floresta 1 e Declividade 1; F1D2 = Floresta 1 e Declividade 2; F1D3 = Floresta 1 e Declividade 3; F2D1 = Floresta 2 e Declividade 1; F2D2 = Floresta 2 e Declividade 2; F2D3 = Floresta 2 e Declividade 3; Y = Tempo (s); DE =Distância (m).

Analisando a Figura 5, observa-se na classe de distância até $100 \mathrm{~m}$ que a produtividade do "Clambunk skidder" foi a mais elevada na classe de floresta 2 (> $\left.350 \mathrm{~m}^{3} / \mathrm{ha}\right)$ e declividade suave $(0$ a $9^{\circ}$ ). Entre as distâncias de 100 a 250 m, o melhor desempenho, em termos de produtividade, foram floresta $1\left(<350 \mathrm{~m}^{3} / \mathrm{ha}\right)$ e declividade ondulada $(9$ a $\left.18^{\circ}\right)$. Na classe de distância até $100 \mathrm{~m}$, verificouse que as produtividades mais baixas ocorreram na floresta 2 ( $\left.>350 \mathrm{~m}^{3} / \mathrm{ha}\right)$ e na declividade ondulada $\left(9\right.$ a $\left.18^{\circ}\right)$. O mesmo aconteceu com as distâncias superiores a $100 \mathrm{~m}$, na floresta $2\left(>350 \mathrm{~m}^{3} / \mathrm{ha}\right)$ e na declividade acidentada (18 a $\left.27^{\circ}\right)$. Houve influência da galhada presente no solo, o que causou empecilho ao deslocamento da máquina, ocorrendo aumento sistemático no tempo do ciclo operacional, em algumas classes de declividade dentro de um tipo de floresta, em comparação com outros tempos nas demais classes de declividade, traduzindo em maiores dificuldades operacionais para a máquina e, conseqüentemente, menores produtividade e maior custo de arraste.

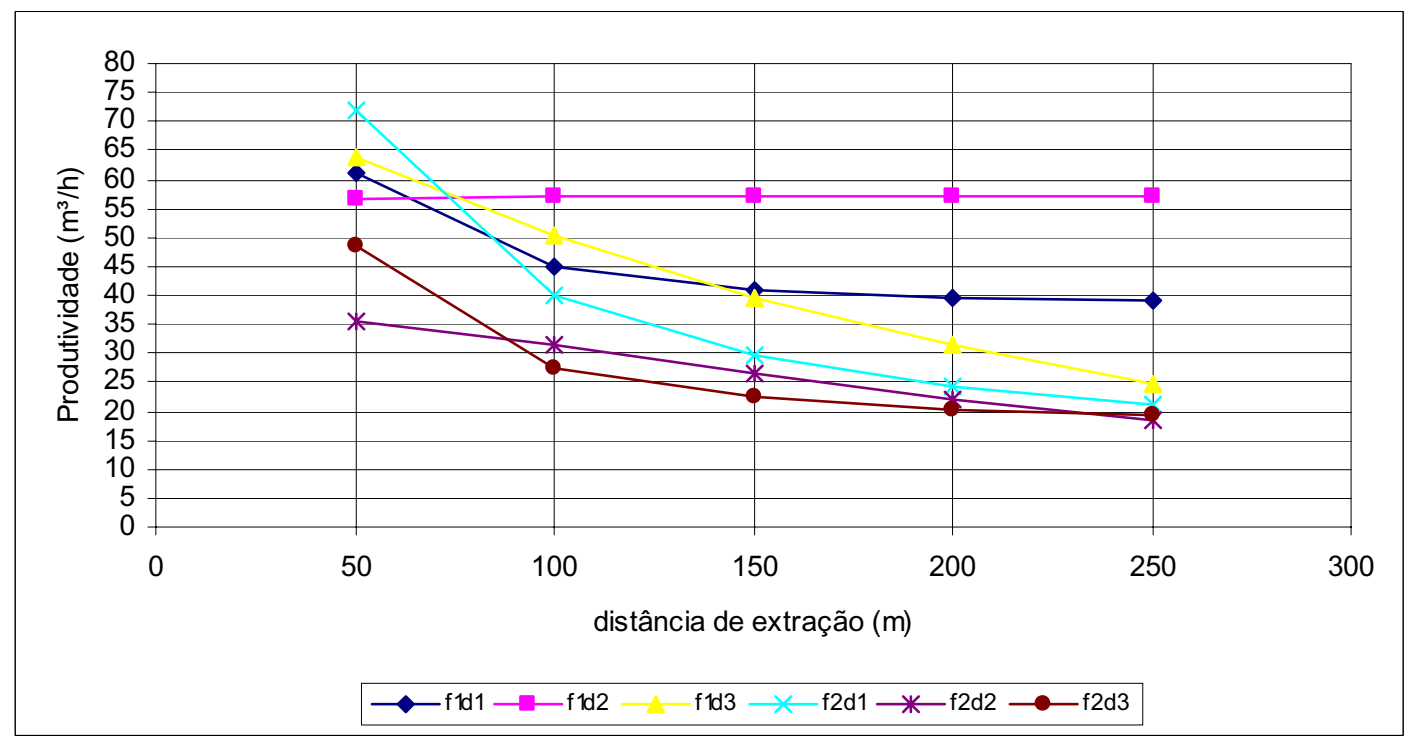

Figura 5. Produtividade média de arraste em função da distância média de arraste 
A Figura 6 apresenta uma curva do tipo exponencial relacionando o custo de arraste em função da produtividade do "Clambunk skidder". Considerando as diferentes produtividades para as diversas declividades de trabalho nesta empresa, o custo de arraste foi calculado com base no custo por hora efetiva de trabalho dividindo pelas produtividades. O custo variou de $\mathrm{R} \$ 14,65 . \mathrm{m}^{-3}$ na faixa de maior declividade do terreno a $\mathrm{R} \$ 3,73 . \mathrm{m}^{-3}$ na faixa de melhores condições de operação.

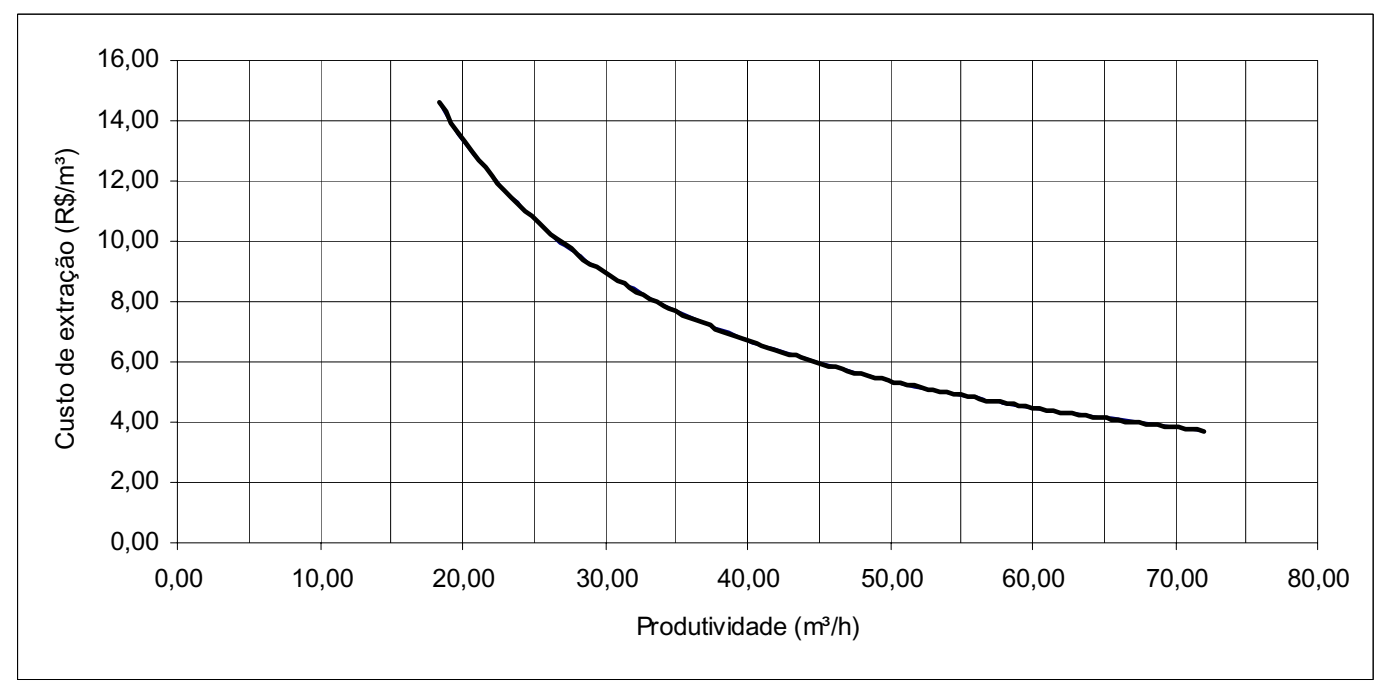

Figura 6. Comportamento do custo de arraste de madeira em função da capacidade operacional.

Em uma pesquisa realizada por Birro (2002), na mesma empresa, mas usando um track skidder para arraste no lugar deste clambunk skidder foi encontrado uma amplitude de variação menor do custo de arraste em relação a produtividade e na distribuição dos custos operacionais obtendo uma maior percentagem nos custos variáveis indiretos em torno de $40 \%$ em comparação com esse trabalho que houve uma maior percentagem nos custos variáveis direto com valores em torno de $47 \%$, que como o clambunk skidder é uma máquina adaptada, mais robusta e preparada para locais mais difíceis de realizar arraste mecanizado, forçando mais todo o equipamento explicando assim esse consumo maior de combustíveis, lubrificantes, peças e pneus/ esteiras.

\section{Conclusões}

Nas condições em que este trabalho foi conduzido e com base na análise e discussão dos resultados, as principais conclusões deste estudo são:

- Em condições de declividade suave e nas áreas de maior produtividade, o custo de arraste foi mais baixo devido ao fato de que a máquina não tem resistência ao seu trabalho e podendo arrastar mais, fazendo assim a produtividade aumentar.

- Os custos menores ocorreram na faixa de declividade ondulada, provavelmente pela resistência imposta pelo terreno;

- Nas áreas em que a produtividade era mais baixa foi onde ocorreram os maiores custos de arraste. 


\section{Referências}

BIRRO, M. H. B. Avaliação técnica e econômica da extração de madeira de eucalipto com "Track-Skidder" em região montanhosa. 2002. Dissertação. (Mestrado em Zootecnia) - Universidade Federal de Viçosa, Viçosa.

FOOD AND AGRICULTURAL ORGANIZATION FAO. Logging and log transport in man-made forests in developing countries. Roma: FAO, 1974. (Forest Paper - FAO,18).

LEITE, A. M. P. Análise de fatores que afetam o desempenho de veículos e o custo de transporte de madeira no distrito florestal do Vale do Rio Doce - MG. 1992. Dissertação. (Mestrado em Ciência Florestal) - Universidade Federal de Viçosa, Viçosa.

LOPES, S. E. Análise técnica e econômica de um sistema de colheita florestal. 2007. Tese. (Doutorado em Engenharia Agrícola) - Universidade Federal de Viçosa, Viçosa.
MACHADO, C. C. Exploração florestal. Viçosa: Ed. da UFV, 1989. v. 6.

Planejamento da colheita. In: Colheita florestal. Viçosa: Ed. da UFV, 2002.

MACHADO, C. C.; MALINOVSKI, J. R. Ciência do trabalho florestal. Viçosa: Ed. da UFV, 1988.

OLIVEIRA, R. J. Avaliação técnica e econômica da extração de madeira de Eucalipto com "Clambunk skidder". 2003. Dissertação. (Mestrado em Ciência Florestal) - Universidade Federal de Viçosa, Viçosa.

SANT'ANNA, G. L.; MACHADO, C. C.; PEREIRA, R. S.; LOPES, E. S. Influência dos parâmetros sociais na colheita florestal. In: CONGRESSO E EXPOSIÇÃO INTERNACIONAL SOBRE FLORESTAS, 6., 2000, Porto Seguro. Anais... Porto Seguro: FOREST, 2000. p. 317-318.

SANTOS, S. L. M. Sistema de apoio à decisão em colheita florestal. 2000. Tese. (Doutorado em Ciência Florestal) - Universidade Federal de Viçosa, Viçosa. 